\title{
CALCULATED CALORIES FOR TRAINING AND THEIR EFFECT ON DEVELOPING SOME PHYSICAL AND BIOMECHANICAL ABILITIES AND ACHIEVING 400-METER RUN FOR YOUTH
}

\author{
Iman Sabeeh Hussein ${ }^{1}$, \\ Bilal Ali Ahmed ${ }^{2 i}$ \\ 1 University of Baghdad, \\ College of Physical Education \\ and Sports Sciences for Girls, \\ Iraq \\ ${ }^{2}$ Ibn Sina University for Medical \\ and Pharmaceutical Sciences, \\ College of Medicine, \\ Iraq
}

\begin{abstract}
:
The research problem arose through researchers' follow-up of training curricula for athletes in athletics in general and 400-meter runners in particular. Most training curricula adopt physical and skill exercises without paying attention to the need for energy appropriate for the effort exerted during the race or training. The Pro Health program - Commerce with Compassion is used in this research to calculate the calories spent during training to find out what is burned during training. The experimental research method is used in this research. The research sample was selected from young 400-meter joggers (9 runners). The arithmetic mean for age is (19.64), a standard deviation is $( \pm 1.5)$, with an arithmetic mean for training age which is (6.6) with a standard deviation $( \pm 1.65)$, an arithmetic mean for mass $(71)$ with a standard deviation $( \pm 2.54)$, an arithmetic mean for height $(172) \mathrm{cm}$, and a standard deviation $( \pm 3.5)$. The results showed that the calories consumed during training changed during training. The differences were statistically in favor of the post-test. The differences energy variable remaining in the body after performing the effort, whether in calories or kilojoules, were not significant. This means that the amounts of energy remained the same, whether in the pre or posttest. The cost of energy per $1 \mathrm{~kg}$ of the body, appeared in the indicator, indicated that the differences are not significant between what the body consumes during physical activity and the remaining calories in the body for both tests. It also showed that there is an imbalance between calories and their output in kilo joules that the sample members take from food, and the calories they burn to make physical effort.
\end{abstract}

i Correspondence: email maher.hasoon@gmail.com, wahbi11951@gmail.com 
Keywords: physical and biomechanical abilities, 400-meter run, calculated calories

\section{Introduction}

The term "energy" was initially associated with mechanical movement or the body's ability to accomplish mechanical work, which helps in achieving the goal of performance as well as the other related aspects: physical, functional and mechanical. The significance of the research lies in the fact that it explores the evaluation of the mechanical and vital energy of 400-meter young athletes in athletics. It also compares between the changes that occur according to diet and physical training (a special speed endurance) and the significance of the changes. The changes are considered as an indicator for evaluating player's health, level of development and calories depletion which reveals the effort harmony and the vital and mechanical energy output according to calories and physical work. The information and data enable specialists in the field of the game to reveal some scientific facts to be considered when training the players of this competition in accordance with the game's physical, functional and mechanical requirements.

The "joule" indicates the body's energy (which leads to the body movement and all the required kinetic actions) that can be measured by the calories spent during the effort. The energy retention law stipulates the amount of energy stability in a particular system (the human body, for example) so that it can convert from one type to another. It is possible to monitor the energy level available to athletes of different distances in athletics, including running 400 meters. It is also possible to monitor what they consume during daily training for each $1 \mathrm{~kg}$ of a lean body to monitor players health and their level of athletic progress according to the type of effort used and its suitability for the type of energy available to these athletes (Manna \& Gulshan, 2013). Carbohydrates are considered one of the main sources for generating thermal energy in the body (Butler et al., 2005), as one gram of these substances gives 4.1 calories. Athletes may need (500-700) grams of carbohydrates in one day, according to the differences in the quality of the sporting activity. The experiments indicated an increase in the actual capacity in the case of giving carbohydrates-rich food. It has been found that when the available energy level falls below the average daily consumption of 30 calories $/ \mathrm{kg}$ (per $1 \mathrm{~kg}$ ) of fat-free mass, a significant impairment of metabolic and hormonal function (Clark, 2003) occurs. This deficiency can affect performance, growth and health. This is because each ATP is equal to $30.5 \mathrm{kcal} / \mathrm{mol}$.

The problem was detected by following up the training curricula of athletes in athletics in general and $400 \mathrm{~m}$ runners in particular. Most of the training curricula adopt physical and skill exercises without paying attention to the need for energy appropriate for the effort exerted during the race or training. On the hand, they do not take into consideration monitoring the physical effort exerted according to the results of mechanical energy and the need of calories suitable for that effort by using the power law and the associated required caloric output. This reflects the need to develop the physical capabilities and the consequent development of the functional and mechanical aspects of 
this competition players. Hence, the researchers wanted to study this topic to develop some solutions related to this aspect to reveal or conclude some scientific facts that have not yet been investigated. The purpose of this study is to determine the amount of work performed during the daily training of $400 \mathrm{~m}$ sprinters, identifying the amounts of calories spent in terms of work performed during daily training, finding out the differences between the pre-tests and the physical tests of the two research groups in anaerobic variants.

Many studies have dealt with this topic. In a study by (Al-Fadhli et al., 2010), the researchers used the experimental method on a sample of 400-meter youth runners. The researchers argued that rationing calorie consumption according to the employment index led to an economical energy expenditure during training and the survival of energy storage after training modules and a significant development in physical abilities (special speed, competition-specific speed endurance, muscle endurance for achievement).

Ajeel and Al-Fadhli (2020) used the experimental method on a sample of 400-meter runners, junior hurdles. They found out that the exercises that were built according to the variables of the centrifugal force through the body mass, the radius of the curve and the circumferential velocity on the curve had a positive effect in improving Completed 400meter hurdles.

Nasser et al. (2019) used the experimental method on a sample of students of the Education Institute in Baghdad. They prepared and applied exercises according to scientific standards based on the type of food suitable for daily exercises to enhance the physical and psychological state and to conclude an ideal and appropriate state to achieve the best achievements. Daily exercise is not commensurate with the daily energy expenditure spent by the research sample, which causes a decrease in the level of achievement. They recommend that an attention should be paid to the type of food appropriate to the level of daily training.

Falcone et al. (2015) used the experimental approach on a sample of active men to compare some different exercises in terms of the number of calories spent during the training session. The training time was fixed. The researchers found out that individuals could burn more calories while performing a HIIT session using HRS (hydraulic resistance system) compared to the same period of time spent in performing a steady intensity training session. This type of sports training may be beneficial for individuals who wish to gain the benefits of both resistance and cardiovascular training but have limited time to devote to the sport.

\section{Method and Tools}

The experimental research method is used in this research. The research sample has been chosen from young 400-meter joggers (9 runners), the arithmetic mean of age is (19.64), the standard deviation is $( \pm 1.5)$, the arithmetic mean for a training age is (6.6) with a standard deviation $( \pm 1.65)$, the arithmetic mean for the mass is (71) with standard 
deviation $( \pm 2.54)$, the arithmetic mean of height is $(172) \mathrm{cm}$, and the standard deviation is $( \pm 3.5)$

The researchers measured body mass, BMI and calories needed to maintain body vitality, according to the (Calculator.net) program, which calculates the above variables after calculating the age, weight, height, gender, and type of activity practiced.

Then, the two researchers used Pro Health -Commerce with Compassion program to calculate the calories spent when training to find out what they burn during training as follows: calculating the type of physical exertion in the designated field or choosing one from the drop-down list from the second field. Then the player's block was calculated. After that, the time of one exercise or the total times that were carried out with training were calculated to estimate the calories that have been burned. By this program the researchers were able to identify the calories spent by each one of the sample members per day. The calories were compared with the corresponding work performed in joules units per $1 \mathrm{~kg}$ of body weight during training days in which the sample members practice speed, endurance, and endurance of special performance training. They were also compared to the type of food required that corresponds to daily energy expenditures with training.

The average daily energy intake for the members of the regular sample was 2870 calories (kilocalories) according to the (Calculator.net) program. The daily energy supply was determined in two days: the pre-test day and the posttests day, as follows: the available calories of the daily food that the sample members eat were according to the types of food they are accustomed to have. The sample members took the following on the two days of the tests:

The total calories available of the daily diet (1730 calories) from the following meals:

1) Breakfast (2 loaf of bread with 2 fried eggs, a cup of tea and milk) is 630 calories.

2) Lunch (100 gm rice dish, with soup, red meat, a loaf of bread and drinks) is 1100 calories. Thus, the total daily calories of the research sample were calculated in order to correspond with the amount of work spent (Wilmore \& Costill, 2005).

3) Comparison of the remaining energy per $1 \mathrm{~kg}$ of body, which is equal to (30.5 kilocalories / per 1 kilogram, equivalent to 128 kilojoules)

4) The sample members were asked to maintain their daily diet during the period between the pre and post-tests and follow their normal eating habits, and during training periods. They were brought to the laboratory once a week to measure their weights and check their food records.

5) The calories obtained from the daily food is (1730 calories).

\section{Research Tests}

1) running 70 meters test from the low start on a curve: to measure the specific speed of a cyclist running 400 meters. Two attempts are given to each member of the 
sample. The time spent is calculated through an approved timer to the nearest tenth of a second.

2) 250-meter running test (anaerobic): to measure the speed endurance of the 400-meter competition.

An attempt is given to each member of the sample and the player starts from standing. It is measured by a certified timer to the nearest tenth of a second.

1) A running test of 600 meters withstand the special performance, given to each member of the sample one attempt, and it is measured to the nearest 1 second.

2) An achievement test for a distance of 400 meters calculated by three timers for each member of the sample according to international law.

3) Applied physical exercises: the method of high intensity interval training was applied and the maximum time for the tests used to determine the training intensity and to calculate the training volumes. Work-to-rest period method was adopted in calculating recovery periods between repetitions of exercises. The researchers calculated the effort expended during daily training in terms of joules and as Follows:

4) Running training $(5 \times 200 \mathrm{~m})$ is equivalent to a volume of 1000 meters, which is equal to a joule according to the weight of the player $(71 \mathrm{~kg})$, equivalent to $(695,800$ kilojoules), which is equivalent to 165,335 kilocalories; thus, the joule performed by training and the equivalent is calculated in calories.

\section{Discussion}

It is noticed, according to Table 1, that there are significant differences in the variables of special velocity, special velocity endurance, muscle endurance, and achievement among the sample members and in favor of the post-test; the velocity variable $(70 \mathrm{~m})$ is statistically significant with an error level which is less than 0.05 , which indicates that the sample members have similar calories resulting from their regularity in a good diet. It also indicates that the results of the physical tests in the post-test have been affected by the training programs that relied on the work and energy and its equivalent calories spent. It is better than the pre-test according to what emerged from the statistically significant differences for this variable.

As for the special speed endurance variable (i.e., the 250-meter test), the differences were statistically significant since the training volumes that were carried out were consistent in terms of caloric expenditure. The reason for these differences is that the body has adapted somewhat to the physical effort according to the vital energy it needs and heat energy resulting from the combustion of foodstuffs; the resulting kinetic energy in terms of (work performed) is in harmony with the calories taken from food, which are consistent with the effort made for the research sample.

As for the special endurance variable (test run 600 meters), the differences are also significant. This means that the vital competency of the members of the research sample has developed as a result of the exercises based on the values of the performed work and 
that oxidation is economically carried out in the post-test in the sample members body cells. The stemming calories result from the metabolic rates required for this effort and according to the energy possessed by the sample members before the effort.

The results indicate that energy and conditioning systems become more efficient and allow for greater duration of exercise and at higher intensity. This axiom is associated with the appropriate quantity and type of food, which can give a positive impact on the development of functional competence and capabilities of the type of activity, which reflects the vital and physical competence and the required work output. The required and appropriate calories can be defined as a cost per $1 \mathrm{~kg}$ of body mass, through the product of work done, measured in kilojoules, in terms of body mass, ground acceleration and distance traveled. Table (2) indicates that there are significant differences between each of the caloric variable available to the sample members between the pre and the post, as the calculated value of $(t)$ is $(2,23)$ with an error level greater than 0.05 . This indicates that the sample members have similar calories resulted from their regular similar diet available to their families. On the other hand, measuring these calories in kilojoules, referred to statistically significant differences, which indicate that the available calories in the post test, in terms of what was achieved by physical work (kinetic energy), is better than the pre-test where the energy storage rate of the research sample in the post test was better than the pre-test according to the statistically significant differences for this variable.

As for the variable of calories spent during training, the differences are statistically significant in favor of the post-test; the training volumes are almost equal in both tests, and that the calorie expenditure is highly economical. The differences indicate the same variable in terms of kilojoules in favor of the post test. These differences were caused by the body adaptation somewhat to the physical effort in accordance with the thermal energy (it needs) resulting from the combustion of foodstuffs. The resulting kinetic energy in terms of (kilojoules) is in harmony with the calories taken from food, which were consistent with the effort made for the research sample.

As for the energy variable remaining in the body after performing the effort, whether in calories or kilojoules, the differences are not significant. This means that the quantities of energy remain the same, whether in the pre or post-test, which indicates that the vital efficiency of the individuals of the research sample regarding the appropriate energy expenditure in the pre-test is similar to the post-test. The oxidation, and the associated heat released from them resulting from the metabolic rates required for this effort in terms of the energy possessed by the sample members before the effort, is done similarly in the body cells of the sample members.

The index of energy indicates that the differences, for each $1 \mathrm{~kg}$ of the body, between what the body consumes during physical activity and the remaining calories in the body for both tests are not significant. It also shows that there is an imbalance between calories and their output in kilojoules that the sample members take from food, and calories they burn to exert physical effort. The indicator indicates that the output was less than 30 calories / $1 \mathrm{~kg}$ (equivalent to 126 kilojoules / kg) of available energy per $1 \mathrm{~kg}$ of 
body mass, which indicates that the calories that the sample members eat do not fulfill the purpose required for physical progress despite its control. This system must be subject to medical supervision in order to raise the physical effort appropriate to the type of calories. It was found that when the available energy level falls below the average daily consumption at a rate of 30 kilocalories (1265 kilojoules) per $1 \mathrm{~kg}$ Fat-free mass leads to a significant impairment of metabolic and hormonal function. This deficiency can affect performance, growth and health.

The level of achievement of the research sample members will be affected because their demolition operations are greater than construction operations as a result of the physical effort they are exposed to, which gives a negative impact on their physical levels development and their achievement. We can identify the required and appropriate calories cost per $1 \mathrm{~kg}$ of body mass, through the product of work done, measured in kilojoules, in terms of body mass, ground acceleration and distance traveled.

\section{About the Authors}

\section{Assit. Prof. Iman Sabeeh Hussein}

Biomechanics in Track and Field, University of Baghdad, College of Physical Education and Sports Sciences for Girls, Iraq. email: sabeeheman@gmail.com

\section{Inst. Dr. Bilal Ali Ahmed}

Biomechanics in Track and Field, Ibn Sina University for Medical and Pharmaceutical Sciences/ College of Medicine, Iraq. email: bilal7279@gmail.com

\section{References}

\section{a. Journals}

Ajeel, Ali Naeem \& Al-Fadhli, Sareeh Abdul-Kareem (2020). Special Exercises in Accordance with the Law of Centrifugation in some Physical Abilities of the Second Curve and the Completion of Running 400 meters Hurdles. Physical Education Journal, (1) 32.

Al-Fadhli, Sareeh Abdul-Kareem et al. (2010). Using Performance Index to Determine the Calories Required for Training and its Effect on Developing some Physical Abilities, Physiological Variables, and Achievement for 400-meter Running Youth. Zangoy Suleimani Journal for Human Studies.

Butler, H., et al. (2005). Consensus Statement of the 1st International Exercise-Associated Hyponatremia Consensus Development Conference, Cape Town, South Africa 2005. Clinical Journal of Sport Medicine, 208-2013.

Falcone, P. H., et al. (2015). Caloric expenditure of aerobic, resistance, or combined highintensity interval training using a hydraulic resistance system in healthy men. J Strength Cond Res., 3.

Manna, I., \& Gulshan, L. (2013). Effect of Training on Selected Biochemical Variables of Elite Male Swimmers. American Journal of Sports Science and Medicine, 13-16. 
Swimmers. American Journal of Sports Science and Medicine, 13-16.

Nasser, N. M., et al. (2019). Training According to The Required Calories as a Function of Muscular Work and its Impact on the Development of Some Physical Abilities and the Achievement of Long Distances Running 5000 Meters;. Indian Journal of Public Health Research \& Development, 10(7).

\section{b. Books}

Clark, N. (2003). Sports Nutrition Guidebook. 3rd ed. Brookline: Human Kinetics.

Wilmore, J. H., \& Costill, D. L. (2005). Physiology of Sport and Exercise (3rd ed.). Human Kinetics Publishing. 


\section{Appendix}

Table 1: The results of the differences

between the pre- and post-tests in the research variables

\begin{tabular}{|c|c|c|c|c|c|c|c|c|}
\hline Variable & $\begin{array}{c}\text { Measure } \\
\text { unit }\end{array}$ & $\begin{array}{c}\text { Pre/ } \\
\text { calories }\end{array}$ & $\begin{array}{c}\text { Post/ } \\
\text { calories }\end{array}$ & $\begin{array}{c}\text { Paired } \\
\text { Differences }\end{array}$ & $\begin{array}{c}\text { Std. } \\
\text { Error } \\
\text { Mean }\end{array}$ & $\mathbf{t}$ & $\begin{array}{c}\text { Error } \\
\text { level }\end{array}$ & Significance \\
\hline $70 \mathrm{~m}$ & second & 8.35 & 8.02 & 0.33 & 0.093 & 3.56 & 0.023 & Significant \\
\hline $250 \mathrm{~m}$ & second & 34.48 & 31.56 & 2.92 & 0.690 & 4.23 & 0.001 & Significant \\
\hline $600 \mathrm{~m}$ & second & 76.07 & 72.54 & 3.53 & 0.842 & 4.19 & 0.031 & Significant \\
\hline $400 \mathrm{~m}$ & second & 53.87 & 50.11 & 3.76 & 0.701 & 5.34 & 0.042 & Significant \\
\hline
\end{tabular}

Table 2: The results of the differences between

the pre and post-tests in the calories of the research sample

\begin{tabular}{|l|l|c|c|c|c|c|c|c|}
\hline Variable & $\begin{array}{l}\text { Measure } \\
\text { unit }\end{array}$ & $\begin{array}{c}\text { Pre/ } \\
\text { calories }\end{array}$ & $\begin{array}{c}\text { Post/ } \\
\text { calories }\end{array}$ & $\begin{array}{c}\text { Paired } \\
\text { Differences }\end{array}$ & $\begin{array}{c}\text { Std. } \\
\text { Error } \\
\text { Mean }\end{array}$ & $\mathbf{t}$ & $\begin{array}{c}\text { Error } \\
\text { level }\end{array}$ & Significance \\
\hline $\begin{array}{l}\text { Available } \\
\text { calories }\end{array}$ & Calories & 1730 & 1740 & 10 & 5.38 & 2.23 & 0.021 & Significant \\
\cline { 2 - 10 } & Kilo joule & 7277 & 7308 & 31 & 8.70 & 3.56 & 0.023 & \\
\hline $\begin{array}{l}\text { Spent } \\
\text { calories }\end{array}$ & calories & 500 & 555.55 & 55.55 & 14.1 & 3.94 & 0.048 & Significant \\
\cline { 2 - 9 } & Kilo joule & 2100 & 2333.31 & 233.34 & 55.5 & 4.23 & 0.001 & Significant \\
\hline $\begin{array}{l}\text { Remaining } \\
\text { energy }\end{array}$ & Calories & 1230 & 1184.45 & 45.55 & 10.5 & 2.34 & 0.068 & Insignificant \\
\cline { 2 - 9 } & Kilo joule & 5166 & 4974.69 & 191.31 & 45.66 & 2.19 & 0.31 & Insignificant \\
\hline $\begin{array}{l}\text { Energy cost } \\
\text { per } 1 \\
\text { kilogram }\end{array}$ & Calories/kg & 20.67 & 19.45 & 1.22 & 0.60 & 2.03 & 0.543 & Insignificant \\
\cline { 2 - 9 } & $\begin{array}{l}\text { Kilo } \\
\text { joule/kg }\end{array}$ & 86.814 & 81.69 & 5.124 & 2.19 & 2.34 & 0.421 & Insignificant \\
\hline $\begin{array}{l}\text { The average } \\
\text { strength of } \\
\text { the two legs } \\
\text { during the } \\
\text { performance }\end{array}$ & Net & 1221.66 & 1431.3 & 209.6 & 50.78 & 10.11 & 0.00 & Significant \\
\hline
\end{tabular}



be applied to their work. Under the terms of this license, no permission is required from the author(s) or publisher for members of the community to copy, distribute, transmit or adapt the article content, providing a proper, prominent and unambiguous attribution to the authors in a manner that makes clear that the materials are being reused under permission of a Creative Commons License. Views, opinions and conclusions expressed in this research article are views, opinions and conclusions of the author(s). Open Access Publishing Group and European Journal of Physical Education and Sport Science shall not be responsible or answerable for any loss, damage or liability caused in relation to/arising out of conflict of interests, copyright violations and inappropriate or inaccurate use of any kind content related or integrated on the research work. All the published works are meeting the Open Access Publishing requirements and can be freely accessed, shared, modified, distributed and used in educational, commercial and non-commercial purposes under a Creative Commons attribution 4.0 International License (CC BY 4.0). 